\title{
STUDI KEANDALAN DEBIT BENDUNG BLOBO DI MOLEK TERHADAP PERUBAHAN AREA LAHAN PERTANIAN
}

\section{A STUDY OF BLOBO DAM'S DISCHARGE RELIABILTY IN MOLEK IRRIGATION THAT CAUSED BY ARGICULTURAL LAND AREA CHANGING}

\author{
Chairil Saleh $^{1}$, Lourina Evanale Orfa ${ }^{2}$, Mas Ragil Nurcahyo ${ }^{3}$ \\ 1,2,3 Jurusan Teknik Sipil Fakultas Teknik Universitas Muhammadiyah Malang \\ Alamat : Jalan Raya Tlogomas 246 Malang 65144 \\ email : chairil@umm.ac.id
}

\begin{abstract}
Molek irrigation is an irrigation channel that irrigates rice fields in Kepanjen District to Sumberpucung District. Before regional space order plan of Malang Regency for 2010 - 2030 is established, the area of agriculture land in both of the districts is 3.971 hectares. Based on the space order plan, some of the agriculture land is planned to be settlement area, so that, the remaining of the land is $2.187 \mathrm{Ha}$. This planning impacts Blobo dam's discharge reliability to irrigate the agricultural land and impacts the existing cropping pattern. The purpose of this research is to determine Blobo dam's discharge reliability to irrigate the agricultural land by using FJ. Mock method and calculate the water requirement. Based on this study the total water requirement for rice fields for one year in existing condition is 6.063,10 liters/second, and in condition caused by planning in the space order plan is 3.325,47 liters/second. By assuming water availability is constant, the total water requirement in extreme condition or Dry Season II is 5.842 liters/second then causes lack of water, while in the space order plan, it causes excess of water. By the analysis process, this study result cropping pattern that minimalize water excess in condition caused by the plan.
\end{abstract}

Keyword : Molek Irrigation, Discharge Reliability

\begin{abstract}
Abstrak
Irigasi Molek adalah saluran irigasi yang mengairi sawah kec Kepanjen sampai dengan Sumberpucung. Sebelum Rencana Tata Ruang Wilayah (RTRW) Kabupaten Malang dari 2010 - 2030 ditetapkan, luas lahan pertanian pada kedua kecamatan tersebut sebesar 3.971 Ha. Pada saat ini sebagian lahan pertanian direncanakan menjadi lahan permukiman sehingga tersisa daerah irigasi $2.187 \mathrm{Ha}$. Hal ini berdampak pada keandalan debit Bendung Blobo dalam mengairi area lahan pertanian, serta berpengaruh pada pola tata tanam yang sudah ada. Tujuan studi untuk mengetahui keandalan debit bendung blobo dalam mengairi area lahan pertanian dengan menghitung kebutuhan air yang tersedia menggunakan Metode FJ. Mock dan menghitung kebutuhan air. Dari studi ini didapatkan total kebutuhan air selama satu tahun untuk tanaman padi pada kondisi existing sebesar $6063.10 \mathrm{ltr} / \mathrm{det}$ dan pada kondisi akibat RTRW sebesar 3325.47 ltr/det. Dengan ketersediaan air diasumsikan tetap, maka total kebutuhan air pada kondisi extrim yaitu Musim Kering II sebesar 5.842 ltr/det yang mengakibatkan kekurangan air dan akibat RTRW mengalami kelebihan Air. Dari analisa tersebut menghasilkan pola tata tanam yang memaksimalkan kelebihan air akibat Rencana Umum Tata Ruang kab. Malang kec. Kepanjen.
\end{abstract}

Kata Kunci : Irigasi Molek, Keandalan Bendung.

\section{PENDAHULUAN}

Usaha untuk meningkatkan suatu produksi tanaman pangan khususnya padi, sebagai suatu komuditas di Indonesia pada dasarnya dapat dilakukan melalui berbagai pendekatan antara lain ekstensifikasi, intensifikasi dan rehabilitasi. Peningkatan produksi pangan dalam jangka waktu pendek dapat dilakukan secara intensifikasi dengan meningkatkan optimalisasi pemanfaatan sumberdaya yang ada, pada usaha tani padi sawah optimalisasi pemanfaatan sumberdaya dapat dilakukan antara lain melalui pemanfaatan air irigasi secara efisien dan efektif.

Penurunan kinerja jaringan irigasi 
merupakan ancaman nyata terhadap kurangnya kebutuhan air untuk sawah. Dampak penurunan kinerja irigasi akan mempengaruhi komitmen petani untuk tetap mempertahankan ekosistem sawah. Hal ini disebabkan oleh buruknya kinerja irigasi yang mengakibatkan lahan tersebut kurang kondusif untuk usaha tani khususnya padi.

Untuk mengetahui tingkat layanan dari suatu irigasi perlu diadakannya penilaian terhadap kinerja jaringan irigasi tersebut. Dalam hal ini petani yang memanfaatkan irigasi molek sebagai sumber air untuk memenuhi kebutuhan air di areal pertanian banyak yang mengalami kekurangan air, hal ini diduga kerena menurunnya kinerja jaringan irigasi yang ada.

Keandalan bendung DI Molek saat ini diperkirakan hanya sekitar $75 \%$ dikarenakan pada musim - musim tertentu seperti musim kemarau pendistribusian air untuk mengairi petak sawah mengalami masalah, dikarenakan pada musim kemarau tersebut sebagian petak sawah pada ujung DI yaitu di juru Sumber pucung sebagian tidak mendapatkan air. Hal tersebut dikarenakan kurangnya jumlah pasokan air dari bendung tersebut.

Akibat adanya rencana umum tata ruang (RUTR) daerah pepanjen untuk mengembangkan area pemukiman yang memakai sebagian area lahan pertanian. Maka akibat dari perubahan fungsi lahan tersebut yang semula adalah area lahan pertanian dan berubah menjadi area pemukiman, kemudian dianalisa seberapa besar perubahan keandalan bendung Blobo DI Molek baik kearah negative atau positif yang output nya bisa direncanakan pola tata tanam (PTT) baru, atau bisa memakai PTT yang sudah ada tetapi bisa dimaksimalkan.

\section{Pengairan}

Penurunan kinerja jaringan irigasi merupakan ancaman nyata terhadap kurangnya kebutuhan air untuk sawah. Dampak penurunan kinerja irigasi akan mempengaruhi komitmen petani untuk tetap mempertahankan ekosistem sawah. Hal ini disebabkan oleh buruknya kinerja irigasi yang mengakibatkan lahan tersebut kurang kondusif untuk usaha tani khususnya padi.

Untuk mengetahui tingkat layanan dari suatu irigasi perlu diadakannya penilaian terhadap kinerja jaringan irigasi tersebut. Dalam hal ini petani yang memanfaatkan irigasi molek sebagai sumber air untuk memenuhi kebutuhan air di areal pertanian banyak yang mengalami kekurangan air, hal ini diduga kerena menurunnya kinerja jaringan irigasi yang ada.

Keandalan bendung DI Molek saat ini diperkirakan hanya sekitar $75 \%$ dikarenakan pada musim - musim tertentu seperti musim kemarau pendistribusian air untuk mengairi petak sawah mengalami masalah, dikarenakan pada musim kemarau tersebut sebagian petak sawah pada ujung DI yaitu di juru Sumber pucung sebagian tidak mendapatkan air. Hal tersebut dikarenakan kurangnya jumlah pasokan air dari bendung tersebut.

Akibat adanya rencana umum tata ruang (RUTR) daerah pepanjen untuk mengembangkan area pemukiman yang memakai sebagian area lahan pertanian. Maka akibat dari perubahan fungsi lahan tersebut yang semula adalah area lahan pertanian dan berubah menjadi area pemukiman, kemudian dianalisa seberapa besar perubahan keandalan bendung Blobo DI Molek baik kearah negative atau positif yang output nya bisa direncanakan pola tata tanam (PTT) baru, atau bisa memakai PTT yang sudah ada tetapi bisa dimaksimalkan.

\section{Irigasi}

Mawardi Erman (2007:5) menyatakan bahwa irigasi adalah usaha untuk memperoleh air yang menggunakan bangunan dan saluran buatan untuk keperluan penunjang produksi pertanian.

Menurut Peraturan Pemerintah No. 25 Tahun 2001 (BAB I pasal 1) tentang irigasi dinyatakan bahwa yang dimaksud dengan irigasi adalah usaha penyediaan dan pengaturan air untuk menunjang pertanian, yang jenisnya meliputi irigasi air permukaan, irigasi air tanah, irigasi pompa, dan irigasi tambak.

Tujuan utama irigasi adalah mewujudkan kemanfaatan air yang menyeluruh, terpadu, dan berwawasan lingkungan, serta meningkatkan kesejahteraan masyarakat, khususnya petani (Peraturan Pemerintah tahun 2001; BAB I pasal 2). Tersedianya air irigasi memberikan manfaat dan kegunaan lain, seperti:

- Mempermudah pengolahan lahan pertanian

- Memberantas tumbuhan pengganggu

- Mengatur suhu tanah dan tanaman 
- Memperbaiki kesuburan tanah

- Membantu proses penyuburan tanah

Dalam pemenuhan kebutuhan air irigasi perlu diusahakan secara menyeluruh dan merata, khususnya apabila ketersediaan air terbatas. Pada musim kemarau misalnya banyak areal pertanian yang tidak ditanami karena air yang dibutuhkan tidak mencukupi.

Dalam memenuhi kebutuhan air irigasi harus menerapkan managemen yang didukung oleh teknologi dan perangkat hukum yang baik. Pemanfaatan sumber daya air diatur sedemikian rupa agar sesuai dengan keperluan tanaman. Pengelolaan yang baik berarti bangunan dan jaringan irigasi serta fasilitasnya perlu dikelola secara tertib dan teratur di bawah pengawasan dan pertanggungjawaban suatu instansi atau organisasi Perkumpulan Petani Pemakai Air (P3A) (Peraturan Pemerintah, 2001).

Ditinjau dari sudut pengelolaannya, sistem irigasi dibagi menjadi :

- Sistem irigasi non teknis yaitu irigasi yang dibangun oleh masyarakat dan pengelolaan seluruh bangunan irigasi dilakukan sepenuhnya oleh masyarakat setempat.

- Sistem irigasi teknis yaitu suatu sistem yang dibangun oleh pemerintah dan pengelolaan jaringan utama yang terdiri dari bendung, saluran primer, saluran sekunder dan seluruh bangunan dilakukan oleh pemerintah, dalam hal ini DPU atau Pemerintah Daerah setempat. Sedangkan jaringan tersier dikelola oleh masyarakat.

Air irigasi yang masuk ke lahan pertanian dapat diketahui dari debit air yang mengalir. Debit adalah volume air yang mengalir melalui suatu penampang melintang dalam alur, pipa, akuifer ambang per satuan waktu (liter/detik) (Soematro, 1986). Debit yang mengalir secara kontinyu melalui pipa atau saluran terbuka bercabang, dengan tampang aliran konstan ataupun tidak konstan adalah sama di semua tampang (titik cabang) (Bambang Triatmojo, 1996:137).

\section{Jaringan Irigasi}

Jaringan irigasi adalah kesatuan dari saluran dan bangunan yang diperlukan untuk pengaturan air irigasi mulai dari penyediaan, pengambilan, pembagian, pemberian, dan penggunaan. Berdasarkan pada Peraturan
Pemerintah No. 25 tahun 2001 tentang irigasi, yang dimaksud dengan jaringan irigasi adalah saluran, bangunan, dan bangunan pelengkap yang merupakan satu kesatuan dan diperlukan untuk pengaturan air irigasi mulai dari penyedian, pengambilan, pembagian, pemberian, penggunaan, dan pembuangannya. Jaringan irigasi ada 2 macam yaitu :

- Jaringan irigasi utama adalah jaringan irigasi yang berada dalam satu sistem irigasi, mulai dari bangunan utama, saluran induk/primer, saluran sekunder, dan bangunan sadap serta bangunan pelengkapnya.

- Jaringan irigasi tersier adalah jaringan irigasi yang berfungsi sebagai prasarana pelayanan air di dalam petak tersier yang terdiri dari saluran pembawa yang disebut saluran tersier, saluran pembagi yang disebut saluran kuarter dan saluran pembuang serta saluran pelengkapnya, termasuk jaringan irigasi pompa yang luas areal pelayanannya disamakan dengan areal tersier.

Berdasarkan pemeliharaan pada jaringan irigasi dapat dibedakan dalam 4 (empat) macam pemeliharaan, yaitu :

- Pemeliharaan rutin : Pemeliharan ringan pada bangunan dan saluran irigasi yang dapat dilakukan sementara selama eksploitasi tetap berlangsung, dimana pemeliharaan hanya bagian bangunan/saluran yang ada di permukaan saja.

- Pemeliharaan berkala : Pemeliharaan yang dilakukan pada bagian bangunan dan saluran dibawah permukaan air, pada waktu melaksanakan pekerjaan ini saluran dikeringkan terlebih dahulu.

- Pemeliharaan pencegahan : Pemeliharaan pencegahan ini adalah usaha untuk mencegah terjadinya kerusakan pada jaringan irigasi akibat gangguan manusia yang tidak bertanggung jawab atau akibat gangguan binatang. 
Pemeliharaan darurat : Pekerjaan yang dilakuan untuk memperbaiki akibat kerusakan yang tidak terduga sebelumnya, misalnya karena banjir atau gempa bumi.

\section{Bendung}

Bendung adalah bangunan air yang dibangun melintang sungai pada lokasi pengambilan air (Direktorat Jendral Sumber Daya Air. 1986. Standar Perencanaan Irigasi). Bangunan tersebut berfungsi untuk menaikkan tinggi permukaan air sungai sehingga air mudah dialirkankan ke saluran irigasi.

Demikian halnya dengan beberapa bendung yang digunakan untuk mengambil air dari D.I. Molek yang bersumber dari bendung Blobo. Bendung tersebut digunakan untuk mengambil air dari DAS Brantas, kemudian disalurkan ke areal persawahan.

\section{Kebutuhan Air}

Kebutuhan air di sawah untuk tanaman padi dapat ditentukan oleh faktorfaktor sebagai berikut (Mawardi Erman 2007:103) :

- Cara penyiapan lahan

- Kebutuhan air untuk tanaman

- Perlokasi dan rembesan

- Pergantian limpasan air

- Curah hujan efektif

Besarnya kebutuhan air dapat ditentukan berdasarkan tenaga kerja yang menangani usaha tani. Keterampilan kerja petani diperoleh melalui pendidikan dan keterampilan turun menurun. Dengan adanya tenaga kerja yang terampil, petani diharapkan dapat mengerjakan lahan pertaniannya dengan baik.

Besarnya kebutuhan air di sawah bervariasi menurut tahap pertumbuhan tanaman dan bergantung pada cara pengelolaan lahan. Besarnya kebutuhan air di sawah dinyatakan dalam $\mathrm{mm} /$ hari

Angka kebutuhan air berdasarkan literatur yang ada yaitu:

- Pengelolaan tanah dan persemaian, selama 1-1,5 bulan dengan kebutuhan air $10-14 \mathrm{~mm} / \mathrm{hari}$.

- Pertumbuhan pertama (vegetatif), selama 1-2 bulan dengan kebutuhan air 4-6 $\mathrm{mm} / \mathrm{hari}$.
- Pertumbuhan kedua (vegetatif), selama 1-1,5 bulan dengan kebutuhan air 6-8 $\mathrm{mm} / \mathrm{hari}$.

- Pemasakan selama lebih kurang 1-1,5 bulan dengan kebutuhan air 5-7 mm/hari.

- Kedalaman air di sawah yang selama ini dilakukan oleh petani yaitu:

- Kedalaman air di sawah setinggi sekitar $2,5-5 \mathrm{~cm}$ dimaksudkan untuk mengurangi pertumbuhan rumput/gulma.

- Kedalaman air di sawah setinggi sekitar 5-10 cm dimaksudkan untuk meniadakan pertumbuhan rumput/gulma.

Tabel 1. Kebutuhan Air untuk Padi Menurut Nodeco/Prosida

\begin{tabular}{ccc}
\hline $\begin{array}{c}\text { Periode } \\
15 \text { hari } \\
\text { ke }\end{array}$ & $\begin{array}{c}\text { Varietas } \\
\text { Biasa } \\
\text { (ltr/dtk/ha) }\end{array}$ & $\begin{array}{c}\text { Varietas } \\
\text { Unggul(ltr/dtk/ha) }\end{array}$ \\
\hline 1 & 1,20 & 1,20 \\
2 & 1,20 & 1,27 \\
3 & 1,32 & 1,33 \\
4 & 1,40 & 1,30 \\
5 & 1,35 & 1,15 \\
6 & 1,25 & 0 \\
7 & 1,12 & - \\
8 & 0 & - \\
\hline
\end{tabular}

Sumber : Dirjen Pengairan, Bina Program PSA 0101985

\section{Pola Tanam}

Pola tanam adalah pembakuan dari pada jenis tanaman yang harus ditanam pada suatu lahan serta periode musim tanam tertentu (Peraturan Bupati 2011. Pedoman Pengaturan Pola Tanam). Tanaman dalam suatu areal dapat diatur menurut jenisnya yaitu monokultur, campuran, dan bergilir. Pola tanam monokultur yaitu menanam tanaman sejenis pada satu areal tanam. Pola tanam campuran yaitu beragam tanaman ditanam pada satu areal. Pola tanam bergilir yaitu menanam tanaman secara bergilir beberapa jenis tanaman pada berbeda di areal yang sama.

Pola tanam dapat digunakan sebagai 
landasan untuk meningkatkan produktivitas lahan. Hanya saja dalam pengelolaannya diperlukan ketrampilan yang baik tentang semua faktor yang menentukan produktivitas lahan tersebut. Biasanya, pengelolaan lahan sempit untuk mendapatkan hasil yang optimal maka pendekatan pertanian terpadu, ramah lingkungan, dan semua hasil tanaman merupakan produk utama adalah pendekatan yang bijak.

Pola tanam merupakan gambaran rencana tanam berbagai jenis tanaman yang akan dibudidayakan dalam suatu lahan beririgasi dalam satu tahun. Faktor yang mempengaruhi pola tanam:

- Ketersediaan air dalam satu tahun

- Prasarana yag tersedia dalam lahan tersebut

- Jenis tanah setempat

- Kondisi umum daerah tersebut

- Kebiasaan dan kemampuan petani setempat

Tujuan pola tanam adalah memanfaatkan persediaan air irigasi seefektif mungkin, sehingga tanaman dapat tumbuh dengan baik. Sedangkan tujuan dari penerapan pola tanam adalah sebagai berikut:

- Menghindari ketidak seragaman tanaman.

- Menetapkan jadwal waktu tanam agar dapat memudahkan dalam usaha pengelolaan air irigasi.

- Peningkatan efisiensi irigasi.

- Persiapan tenaga kerja untuk penyiapan tanah agar tepat waktu.

- Peningkatan hasil produksi petani.

Penentuan jenis pola tanam disesuaikan dengan debit air yang tersedia pada setiap musim tanam. Jenis pola tanam suatu daerah irigasi dapat digolongkan menjadi :

1. Padi - padi

2. Padi - padi - palawija

3. Padi-palawija-palawija

\section{Pemberian Air}

Pemberian air irigasi adalah penyaluran alokasi air dari jaringan utama ke petak tersier dan kuarter (Peraturan Pemerintah tahun 2001). Ditinjau dari cara pemberian air, jaringan irigasi dibedakan menjadi empat macam cara yaitu :

- Jaringan irigasi permukaan (aliran yang diambil melalui sungai, danau, dan sumber air lainnya kemudian dialirkan ke petak-petak sawah).

- Jaringan irigasi air tanah dalam (menggunakan sumur bor/resapan, dengan cara memompa air tersebut dengan pompa air kemudaian dialirkan ke petak-petak sawah).

- Jaringan irigasi sistem pantek atau pancaran dengan menggunakan alat sprinkler.

- Jaringan irigasi dengan cara tetesan (trickle irrigation), yaitu sistem irigasi dengan memakai pipa-pipa yang ditempatkan pada tempat tertentu sebagai jalan keluarnya air dengan cara menetes di atas tanah.

Walaupun pada kenyataanya irigasi sangat dibutuhkan oleh masyarakat, tetapi masyarakat sering mengabaikan pemeliharaan akan bangunan fisik irigasi sehingga sering timbul permasalahan-permasalahan.

Oleh karena itu, dalam penelitian ini akan diupayakan peningkatan efisiensi jaringan irigasi air permukaan dalam memenuhi kebutuhan air pada areal pertanian di DI Molek.

Keberadaan jaringan irigasi dari DAS blobo memberikan beberapa keuntungan bagi penduduk kepanjen. Yaitu Memudahkan petani dalam mengairi lahan pertanian tanpa harus menunggu musim penghujan.

Mendukung program intensifikasi pertanian tanaman padi atau tanaman palawija yang peningkatannnya sangat signifikan dalam bentuk table prosentase.

\section{Ketersediaan Air Dengan Metode F.J. Mock}

F.J. Mock pada tahun 1973 mengusulkan suatu model simulasi keseimbangan air bulanan untuk daerah pengaliran di Indonesia. Model perhitungan ini didapat dari hujan, evapotranspirasi, tanah dan tampungan air tanah.

Model ini diterangkan dalam makalahnya Guideline PSA 001 sebagai suatu pendekatan perkiraan debit bulanan. Buku pedoman ini menekankan bahwa, tidak ada debit bangkitan yang dapat dipercaya, sampai debit tersebut dikalibrasi dengan debit penga matan. Model Mock ini juga disarankan didalam Standar Perencanaan Irigasi KP-01, tetapi tanpa uraian lebih lanjut bagaimana cara menggunakannya. Cara Mock ini cukup 
sederhana dalam perhitungannya dan terbukti sangat populer dikalangan konsultan Indonesia. Sangat banyak contoh perhitungan yang salah, karena para pengguna tidak mempelajari acuan yang asli, akan tetapi mengikuti studi kasus yang telah ada. Juga banyak para pengguna tidak biasa memperhatikan atau mencoba pilihan parameter yang ada. Hal ini terbukti dari banyaknya parameter yang digunakan diambil secara langsung dari studi kasus yang telah ada tanpa mengadakan pengecekan lebih lanjut pada pengguna annya. Kesalahan umum yang lain yang terjadi adalah tidak cukupnya data hujan dalam satu tahun secara berurutan dalam tenggang waktu tertentu.

Mock (1973) menjelaskan metode untuk menduga debit aliran sungai dengan tahapan - tahapan sebagai berikut :

Rumus untuk menghitung aliran permukaan terdiri dari :

- Evapotranspirasi Terbatas (Limited Evapotranspiration)

$$
\begin{aligned}
& \Delta S=P-E T_{p} \\
& E / E T_{p}=(m / 20) .(18-n) \\
& E=E t_{p} \cdot(m / 20) \cdot(18-h) E T_{t} \\
& E T_{a}=E T_{p}-E
\end{aligned}
$$

- Keseimbangan Air (Water Balance)

$$
\begin{aligned}
& W S=P-S S(\Delta S) \\
& S S=S M C_{n}-S M C_{n-1} \\
& S M C_{n}=S M C_{n-1}+P_{1}
\end{aligned}
$$

- Neraca air di bawah permukaan

$d V_{n} \quad=V_{n}-V_{n^{-1}} W S$

$I \quad=i . W S d V_{n}$

$V_{n} \quad=1 / 2 \cdot(1+k) \cdot I+k \cdot V_{n-1}$

- Aliran permukaan

$$
\begin{array}{ll}
R_{o} & =B F+D R_{o} \\
B F & =1-d V_{n} \\
D R_{o} & =W S-I
\end{array}
$$

Keterangan :

$$
\begin{array}{ll}
\Delta \mathrm{S} & =\text { Hujan netto }(\mathrm{mm}) \\
\mathrm{P} & =\text { Hujan }(\mathrm{mm}) \\
\text { ETp } & =\text { Evapotranspirasi potensial }(\mathrm{mm}) \\
\text { ETa } & =\text { Evapotranspirai terbatas }(\mathrm{mm}) \\
\mathrm{WS} & =\text { Kelebihan air }(\mathrm{mm}) \\
\mathrm{SS} & =\text { Kandungan air tanah }(\mathrm{mm}) \\
\mathrm{SMC} & =\text { Kelembaban tanah }(\mathrm{mm}) \\
\mathrm{dV} & =\text { Perubahan kandungan air tanah } \\
& \text { (mm) } \\
\mathrm{V} & =\text { Kandungan air tanah }(\mathrm{mm}) \\
\mathrm{I} & =\text { Laju infiltrasi }(\mathrm{mm} / \mathrm{dt}) \\
\mathrm{i} & =\text { Koefisien infiltrasi }(<1) \\
\mathrm{k} & =\text { Koefisien resesi aliran air tanah }(<1) \\
\text { DRo } & =\text { Aliran langsung }(\mathrm{mm})
\end{array}
$$

$$
\begin{array}{ll}
\mathrm{BF} & =\text { Aliran air tanah }(\mathrm{mm}) \\
\mathrm{Ro} & =\text { Aliran permukaan }(\mathrm{mm}) \\
\mathrm{n} & =\text { Jumlah hari kalender dalam } 1 \text { bulan } \\
\mathrm{m} & =\text { Bobot lahan yang tidak tertutup } \\
& \text { vegetasi }(0<\mathrm{m}<50 \%)
\end{array}
$$

\section{METODE PENELITIAN}

Peneliti mengambil lokasi penelitian pada area sawah di DI Molek Kecamatan Kepanjen, Kabupaten Malang, Jawa Timur yang mempunyai luas area irigasi seluas $3971 \mathrm{Ha}$.

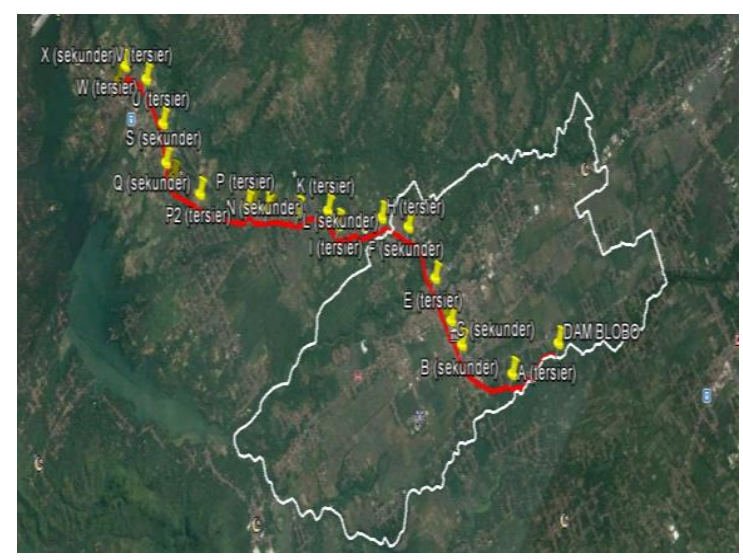

Gambar 1. Lokasi Studi Penelitian

\section{Metode Pengumpulan Data \\ Observasi Lapangan}

Observasi dalam penelitian ini digunakan untuk mendapatkan informasi dan data yang tidak diperoleh dari pustaka serta membuktikan kebenaran data-data umum yang diperoleh dari pustaka.

Data observasi yang diperoleh bersifat deskriptif faktual, cermat, dan terperinci mengenai keadaan di lapangan, kegiatan manusia, situasi sosial, serta kontak kegiatan.

\section{Dokumentasi}

Bentuk dokumen yang digunakan meliputi data-data, catatan, transkrip buku, dokumen, peraturan notulen, dan lain sebagainya. Metode ini dapat dipelajari dari buku dan referensi yang ada hubungannya dengan materi dalam penelitian ini. Data-data yang didapat yaitu data mengenai : debit, hasil produksi, dan rencana masa tanam.

\section{Wawancara}

Bentuk pengumpulan data dengan cara ini dilakukan guna mendapatkan keterangan, saran, dan tanggapan secara langsung dari pihak-pihak yang bersedia diwawancarai. Pihak-pihak tersebut adalah :

- Staf dan karyawan dari DPU Pengairan 
Kepanjen,

- Staf dan karyawan dari UPTD Sumber Daya Air dan Irigasi Kepanjen,

- Staf dan karyawan dari Dinas Cipta Karya dan Tata Ruang kabupaten Malang.

- Petani kec. Kepanjen.

\section{Data Penelitian}

Dalam mencari dan mengumpulkan data, peneliti memperoleh melalui berbagai sumber antara lain :

- Dokumen, peraturan, notulen dan sejenisnya peneliti dapatkan dari DPU Pengairan Kepanjen, UPTD Sumber Daya Air dan Irigasi Kepanjen, Dinas Cipta Karya dan Tata Ruang kabupaten Malang.

- Penjelasan dan pengetahuan mengenai irigasi, jaringan irigasi dan sebagainya, peneliti dapatkan melalui buku, dan transkrip.

Foto, gambar, dan keterangan lainnya peneliti dapatkan melalui observasi di lapangan dan wawancara.

\section{Desain Penelitian}

Dalam penelitian ini digunakan pendekatan kuantitatif bersifat deskriptif, artinya permasalahan yang dibahas dalam penelitian ini bertujuan untuk menjelaskan keadaan status fenomena yaitu mengetahui hal-hal yang berhubungan dengan keadaan sesuatu sesuai dengan fenomena atau gejala yang terjadi.

Saluran yang akan diteliti adalah DI Molek yang sumber airnya berasal dari Bendung Blobo. Dari penelitian ini akan diketahui volume air yang diperlukan untuk kebutuhan lahan pertanian tersebut.

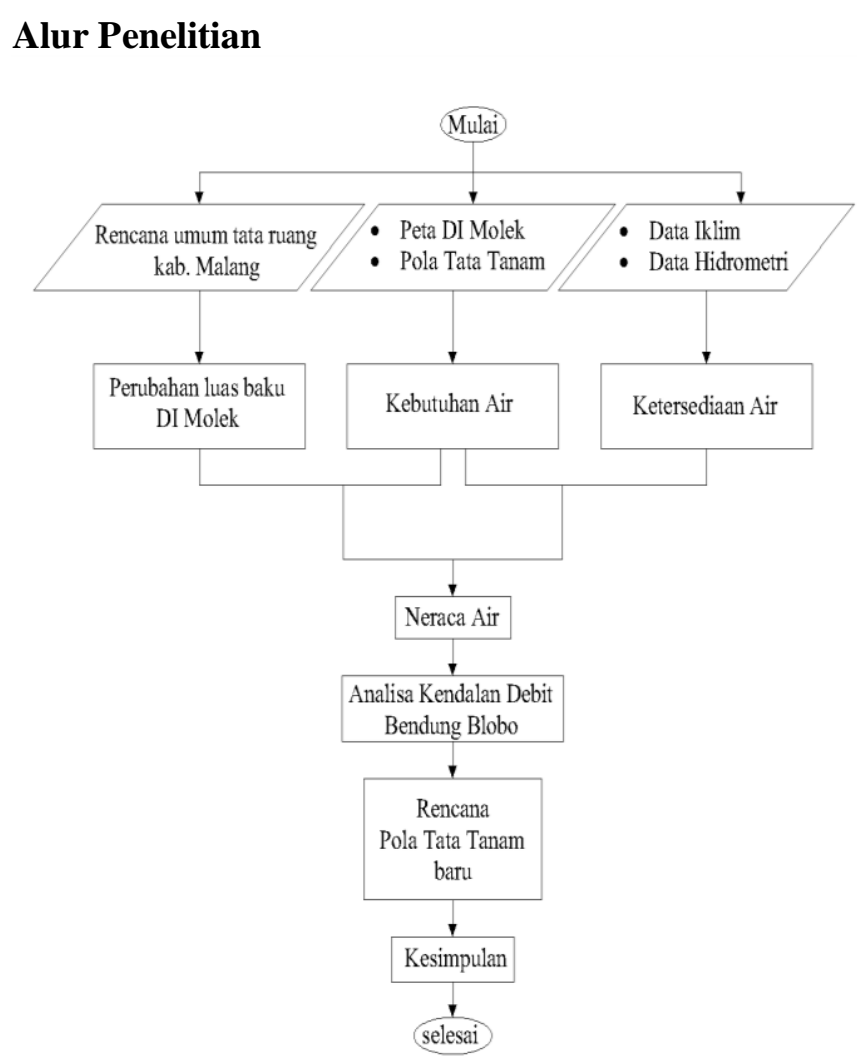

Gambar 2. Bagan Alur Penelitian

\section{Analisa Data}

Analisis data dalam penelitian ini meliputi :

- Pengumpulan data.

- Skema jaringan irigasi.

- Data pola tata tanam (PTT).

- Peta Daerah Irigasi.

- Data iklim.

- Data hidrometri.

- Data peta Das Kali Brantas

- Rencana Umum tata ruang (RUTR) kab. Malang.

- Menghitung ketersediaan air di Bendung Blobo.

- Menghitung kebutuhan Air DI Molek.

- Analisa Neraca Air kondisi Existing.

- Mehitung perubahan luas area Irigasi berdasarkan RUTR.

- Menghitung kebutuhan Air setelah adanya perubahan akibat RUTR.

- Analisa neraca air setelah terjadi perubahan lahan.

- Optimalisasi pemanfaatan air dengan rencana PTT baru. 


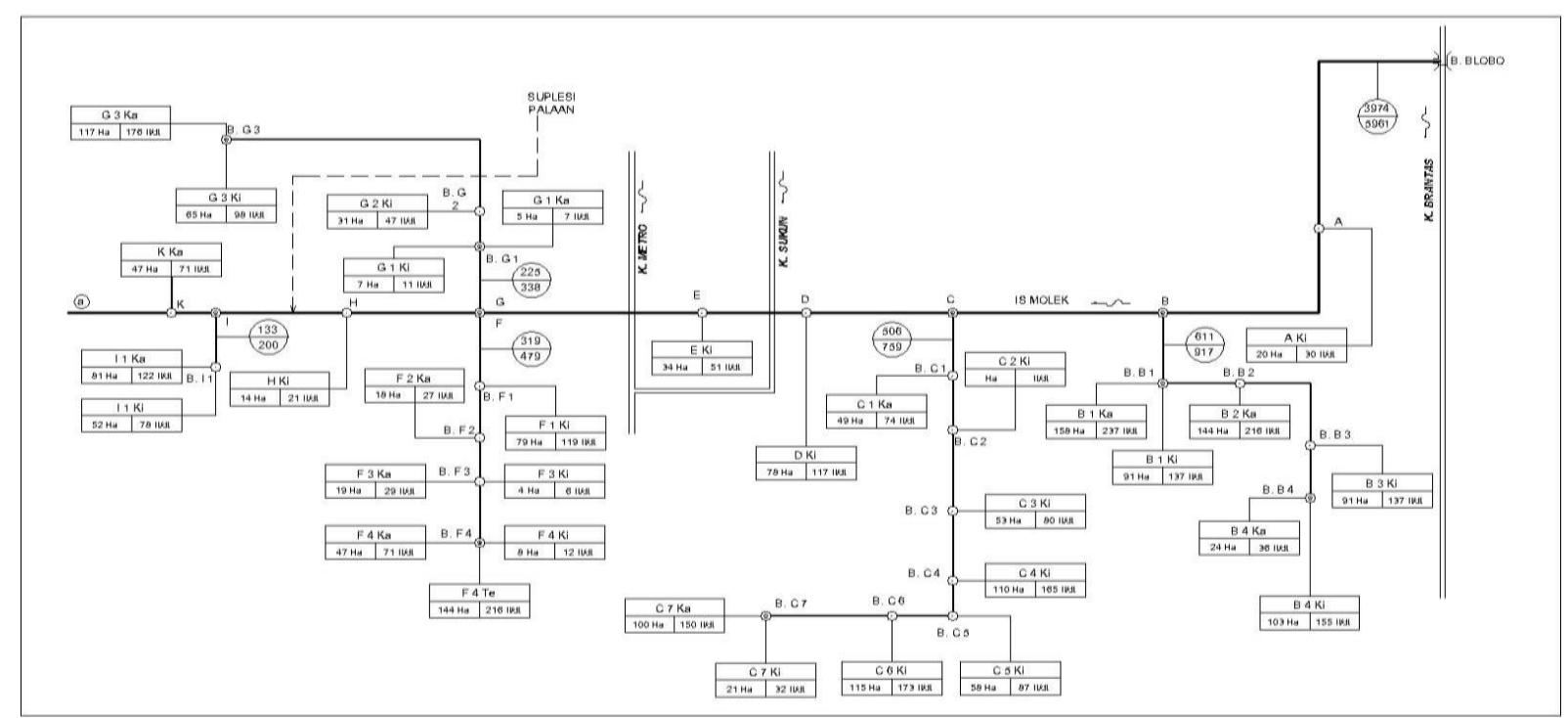

Gambar 3. Deskripsi Saluran irigasi Molek petak A - K kepanjen

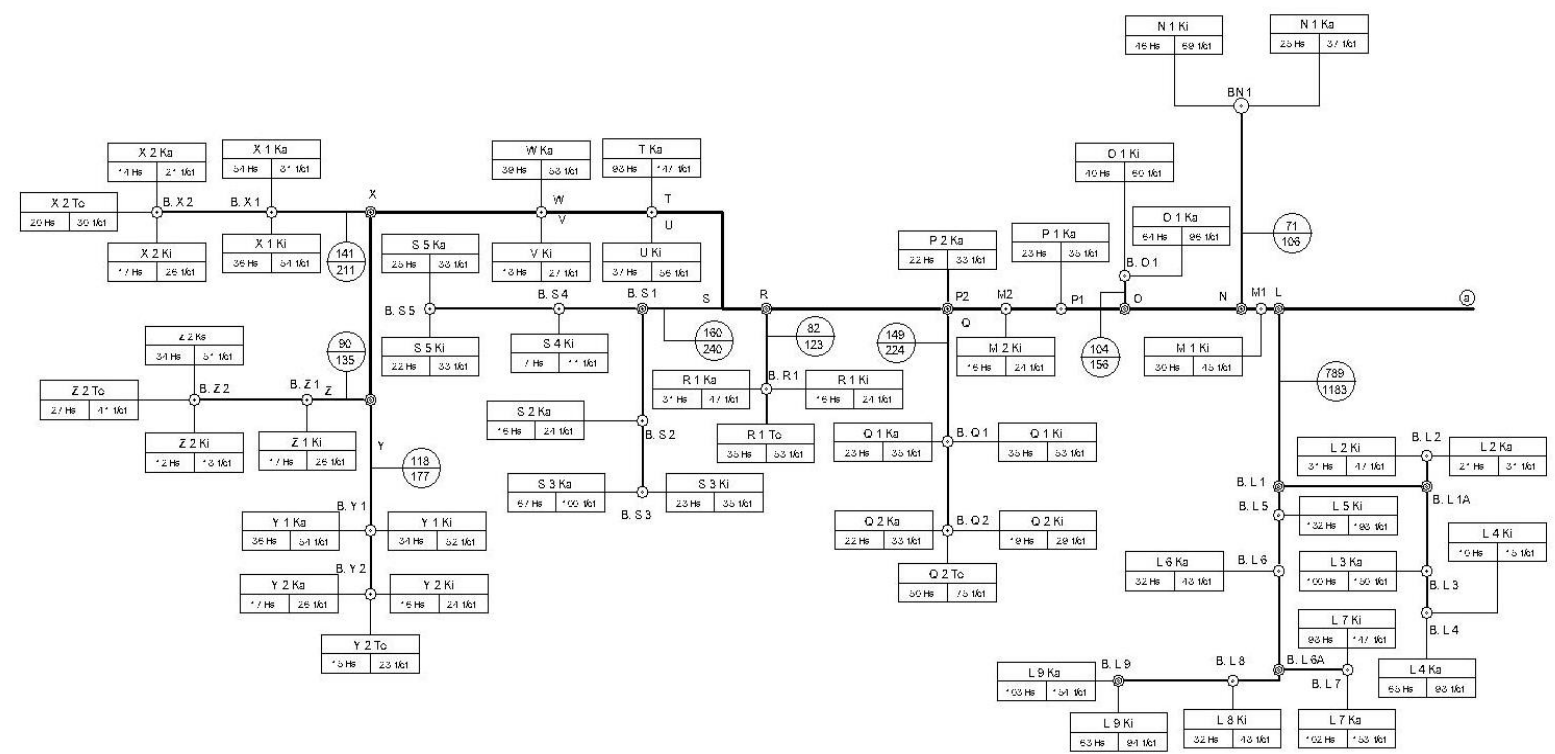

Gambar 4. Deskripsi Saluran irigasi Molek petak L - Z kepanjen

HASIL DAN PEMBAHASAN

Analisa Ketersediaan Air

Langkah - langkah pendugaan debit aliran yang tersedia dengan model $F$ J. Mock

Di ambil contoh bulan Januari

- Input data curah hujan bulanan (P), temperature $(\mathrm{t})$, penyinaran matahari (S), kelembaban relative (h), kecepatan angin (w). (data lengkap terlampir)

- Menentukan besarnya nilai evapotranspirasi aktual $\left(E t_{a}\right)$
- Input data Evapotranspirasi potensial $\left(E T_{p}\right)$ pada bulan Januari yang di diperoleh dari perhitungan sebelumnya yakni sebesar 133,328 $\mathrm{mm} / \mathrm{bln}$.

- Menentukan besarnya parameter permukaan lahan terbuka $(m)$. Untuk lahan pertanian yang di olah (sawah dan ladang) ditaksir harga $m$ sebesar $50 \%$. 


$$
\begin{aligned}
& \text { ○ } \begin{aligned}
\frac{m}{20} \cdot(18 & -n)=\frac{0,5}{20} \cdot(18-18)= \\
0,00 & \\
& =E T_{p} \cdot(m / 20) \cdot(18-h) \\
& =133,366 \cdot 0,00 \\
& =0,00 \\
& =E T_{p}-E \\
& =133,366-0,00 \\
& =133,366 \mathrm{~mm} / \mathrm{bln}
\end{aligned} \\
& \text { ○ }
\end{aligned}
$$

- Menentukan besarnya parameter keseimbangan air dalam tanah

- Menghitung besarnya air hujan yang mencapai permukaan tanah $(\Delta S)$

$$
\begin{aligned}
\Delta S & =P-E T_{a} \\
& =249,00-133,366 \\
& =115,634 \mathrm{~mm} / \mathrm{bln}
\end{aligned}
$$

- Menentukan besarnya kandungan kelembaban air tanah. Jika nilai $\Delta S>$ 0 , maka kandungan kelembaban air di dalam tanah adalah 0 , sebaliknya jika $\Delta S<0$, maka besarnya kandungan kelembaban air dalam tanah adalah nilai $\Delta S$ itu sendiri, ini berarti bila harga $\Delta S$ positif $\left(P>E T_{a}\right)$ maka air akan masuk ke dalam tanah bila kapasitas kelembaban tanah belum terpenuhi, dan sebaliknya akan melimpas bila kondisi tanah jenuh. Bila harga $\Delta S$ negatif $(R<E T a)$, sebagian air tanah akan keluar dan terjadi kekurangan (deficit). Pada bulan Januari $P>E T_{a}$ sehingga $\Delta S>$ 0 , oleh karena itu besarnya kandungan kelembaban air tanah pada bulan Januari adalah 0 .

- Menentukan parameter kapasitas kelembaban tanah $(S M C)$. Nilai $S M C$ awal pada bulan Januari periode pertama ditaksir sebesar $250 \mathrm{~mm}$. Untuk bulan / periode berikutnya, tergantung dari nilai kandungan kelembaban air dalam tanah. Jika nilainya negatif, maka besarnya $S M C$ pada bulan berikutnya merupakan seleisih dari nilai $S M C$ bulan / periode sebelumnya dengan nilai $\Delta S$ pada bulan berikutnya.

- Menentukan besarnya kelebihan air di permukaan tanah $(W S)$. Besarnya $W S$ tergantung dari nilai nilai $\Delta S$. Jika $\Delta S$ $>0$ artinya permukaan tanah mendapat kelebihan air sebesar $\Delta S$. Namun jika $\Delta S<0$ artinya permukaan tanah tidak kelebihan air, justru kandungan air tanahnya berkurang sebesar $\Delta S$. Jadi pada bulan Januari periode pertama nilai $W S$ sama dengan nilai $\Delta S$ yakni sebesar 115,672 $\mathrm{mm} / \mathrm{bln}$.

- Menentukan besarnya aliran dan tampungan air tanah

- Menghitung besarnya Infiltrasi ( $I$ ).

$$
\begin{aligned}
I & =W S . i \\
& =115,634 \cdot 0,5 \\
& =57,817 \mathrm{~mm} / \mathrm{bln}
\end{aligned}
$$

$i$ adalah nilai parameter, yakni koefisien infiltrasi bersasarkan kondisi porositas tanah dan kemiringan daerah pengaliran. Untuk daerah ini ditaksir harga $i$ sebesar 0,5 .

○ $0,5 \cdot(1+k) I=0,5 \cdot(1+0,7)$. $57,836=49,160 \mathrm{~mm} / \mathrm{bln}$

$k$ adalah besarnya parameter, yakni faktor resesi aliran air tanah yang ditaksir sebesar 0,7

○ $k \cdot V_{(n-1)}=0,7 \cdot 1000=700$

$V_{(n-1)}$ adalah kandungan air tanah pada bulan sebelumnya. Untuk penentuan pada awal bulan (initial storage) ditaksir sebesar $1000 \mathrm{~mm}$.

- Menentukan besarnya volume penyimpanan air tanah $\left(V_{n}\right)$

$$
\begin{aligned}
V_{n} & =k \cdot V_{n}-1+1 / 2(1+k) . I \\
& =700+49,145 \\
& =749,145 \mathrm{~mm} / \mathrm{bln}
\end{aligned}
$$

- Menentukan besarnya perubahan volume air $\left(d V_{n}\right)$

$$
\begin{aligned}
d V n & =V_{n}-V_{n-1} \\
& =749,160-1000 \\
& =-250,855 \mathrm{~mm} / \mathrm{bln}
\end{aligned}
$$

- Menentukan besarnya aliran dasar $(B F)$

$$
\begin{aligned}
B F & =I-d V_{n} \\
& =57,817-(-250,855) \\
& =308,673 \mathrm{~mm} / \mathrm{bln} \\
& \text { besarnya aliran } \\
\text { Menentukan } & \\
\text { permukaan }\left(D R_{o}\right) & \\
D R_{o} \quad & W S-I \\
= & 115,672-57,817 \\
= & 57,817 \mathrm{~mm} / \mathrm{bln}
\end{aligned}
$$

- Menentukan besarnya aliran $\left(R_{o}\right)$

$$
\begin{array}{cc}
R_{o} \quad & B F+D R_{o} \\
= & 308,673+57,817 \\
= & 366,490 \mathrm{~mm} / \mathrm{bln}
\end{array}
$$


- Menentukan besarnya debit aliran sungai pada DAS

$$
\begin{aligned}
\mathrm{Q}= & \frac{R_{o}}{1000} \cdot A \cdot 10 .^{6} /(n \cdot 24 \cdot 3600) \\
& \frac{366,490}{1000} \cdot 875,72.10 .^{6} /(31 \cdot 24 \cdot 3600) \\
= & 119,8 \mathrm{~m}^{3} / \mathrm{dt}
\end{aligned}
$$

Jadi besarnya debit aliran sungai yang mengalir pada daerah tangkapan air Bendung Akir pada Bulan Januari adalah sebesar 0,632 $\mathrm{m}^{3} / \mathrm{dt}$.

Parameterisasi Model F.J. Mock di lakukan dengan cara mencoba - coban nilai dari parameter Model F.J. Mock seperti singkapan lahan (m), koefisien infiltrasi (i), kapasitas kelembaban tanah $(S M C)$, penyimpanan awal $(I S)$, dan faktor resesi aliran air tanah $(\mathrm{k})$ hingga mendapatkan $\mathrm{Q}$ model (debit hasil pendugaan Model F.J. Mock) yang nilainya mendekati nilai $\mathrm{Q}$ observasi (debit hasil pengukuran lapangan).

\begin{tabular}{|c|c|c|c|c|c|c|}
\hline $\begin{array}{l}\mathrm{N} \\
\mathrm{o}\end{array}$ & $\begin{array}{c}\mathrm{P} \\
(\mathrm{mm} \\
\quad)\end{array}$ & $\begin{array}{l}\text { ETo } \\
(\mathrm{mm})\end{array}$ & $\begin{array}{c}\mathrm{GW} \\
\mathrm{S} \\
(\mathrm{mm} \\
)\end{array}$ & $\begin{array}{c}\mathrm{BF} \\
(\mathrm{mm} \\
)\end{array}$ & $\begin{array}{c}\text { Ro } \\
(\mathrm{mm} \\
\text { ) }\end{array}$ & $\begin{array}{l}\text { Qmo } \\
\mathrm{d} \\
\mathrm{m}^{3} / \mathrm{dt}\end{array}$ \\
\hline 1 & 249 & 133.4 & $\begin{array}{c}115 . \\
6\end{array}$ & $\begin{array}{c}308 . \\
7\end{array}$ & $\begin{array}{c}366 . \\
5\end{array}$ & 119.8 \\
\hline 2 & 315 & 117.3 & $\begin{array}{c}200 . \\
6\end{array}$ & $\begin{array}{c}239 . \\
8\end{array}$ & $\begin{array}{c}340 . \\
1\end{array}$ & 123.1 \\
\hline 3 & 314 & 124.9 & $\begin{array}{c}195 . \\
3\end{array}$ & $\begin{array}{c}197 . \\
6\end{array}$ & $\begin{array}{c}295 . \\
2\end{array}$ & 96.5 \\
\hline 4 & 268 & 115.5 & $\begin{array}{c}167 . \\
0\end{array}$ & $\begin{array}{c}165 . \\
5\end{array}$ & $\begin{array}{c}249 . \\
0\end{array}$ & 84.1 \\
\hline 5 & 175 & 109.7 & 92.8 & $\begin{array}{c}135 . \\
3\end{array}$ & $\begin{array}{c}181 . \\
7\end{array}$ & 59.4 \\
\hline 6 & 101 & 104.2 & 30.7 & $\begin{array}{c}104 . \\
0\end{array}$ & $\begin{array}{c}119 . \\
3\end{array}$ & 40.3 \\
\hline 7 & 28 & 115.3 & 0.0 & 75.1 & 75.1 & 24.6 \\
\hline 8 & 11 & 115.4 & 0.0 & 52.6 & 52.6 & 17.2 \\
\hline 9 & 34 & 125.4 & 0.0 & 36.8 & 36.8 & 12.4 \\
\hline 10 & 88 & 134.7 & 0.0 & 25.8 & 25.8 & 8.4 \\
\hline 11 & 211 & 134.4 & 24.8 & 19.9 & 32.3 & 10.9 \\
\hline 12 & 550 & 139.3 & $\begin{array}{c}360 . \\
1\end{array}$ & 42.8 & $\begin{array}{c}222 . \\
8\end{array}$ & 72.8 \\
\hline
\end{tabular}

Tabel 2. Komponen Neraca Air DAS Brantas Menggunakan Model F.J. Mock

Sumber : Hasil Perhitungan

$$
\begin{aligned}
& \text { Rata }- \text { rata KAR } \\
& \text { Keterangan : }
\end{aligned}
$$
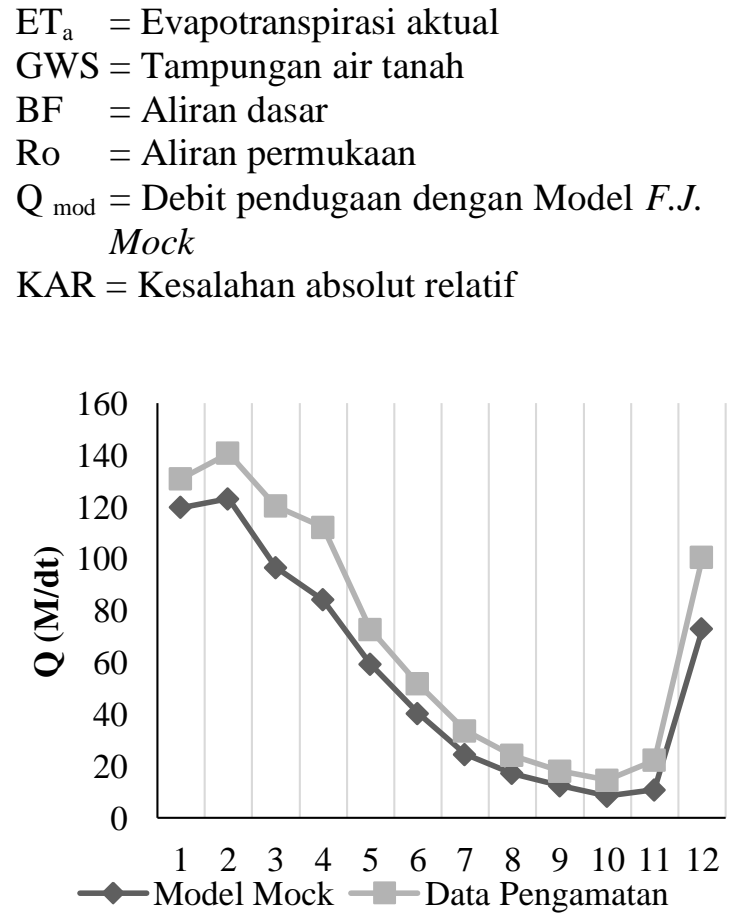

Gambar 5. Grafik Perbandingan Debit Aliran Sungai DAS Brantas Hasil Pendugaan Model F.J. Mock dan Debit Hasil tahun 2015

\section{Kebutuhan Air}

\section{Perhitungan NFR}

Pada kondisi existing, pola tata tanam menggunakan sistem Musim Hujan (MH), musim kemarau 1 (MK-1), dan musim kemarau 2 (MK-2). Perhitungan NFR di bututuhkan data koefisien tanaman, evapotranspirasi, $\mathrm{CH}$ efektif (Rc) Contoh perincian perhitungan NFR Perhitungan pada periode nop-2 (LP)

$>$ Diketahui,

- $\mathrm{P}=2.00$

- $\mathrm{S}=300 \mathrm{~mm}$

- $\mathrm{T}=30$ hari

- ET0 $=5,4 \mathrm{~mm} / \mathrm{hari}$

- $\mathrm{Re} \quad=0,56 \mathrm{~mm} / \mathrm{hr}$

$\mathrm{NFR}=\mathrm{IR}+\mathrm{ETC}+\mathrm{RW}+\mathrm{P}-\mathrm{Re}$

$\checkmark \mathrm{M}=1,1 \times \mathrm{ET} 0+\mathrm{P}$

$\mathrm{M}=1,1 \times 5,4+2,00$

$$
\begin{aligned}
& =7,94 \\
\mathrm{k} & =\mathrm{M} \cdot \mathrm{T} / \mathrm{S} \\
\mathrm{k} & =7,94 \times 30 / 300 \\
& =0,79 \\
\checkmark \quad \mathrm{IR} & =\left(\mathrm{M} \cdot \mathrm{e}^{\mathrm{k}}\right) /\left(\mathrm{e}^{\mathrm{k}}-1\right) \\
\mathrm{IR} & =\left(7,94 \cdot \mathrm{e}^{0.79}\right) /\left(\mathrm{e}^{0,79}-1\right) \\
\mathrm{IR} & =14,49 \mathrm{~mm} / \mathrm{hari}
\end{aligned}
$$

NFR $=$ Penggunaan konsumtif $+\mathrm{P}+\mathrm{IR}+$ WLR - Re

$\mathrm{NFR}=0+2,00+14,49+0-0,56$ 
$=15,93$

$\mathrm{NFR}=(15,93 \times 10000) /(24 \times 60 \times 60)$

NFR $=1,84$ liter $/ \operatorname{det} /$ hari

Perhitungan pada periode Jan-1 (PADI)

Diketahui,

$$
\begin{aligned}
& \text { - } \mathrm{P}=2.00 \\
& \text { - } \mathrm{S}=300 \mathrm{~mm} \\
& \text { - } \mathrm{T}=30 \text { hari }
\end{aligned}
$$

- $\mathrm{ET} 0=4,4 \mathrm{~mm} / \mathrm{hari}$

- $\operatorname{Re} \quad=2,31 \mathrm{~mm} / \mathrm{hr}$

NFR $=$ Penggunaan konsumtif $+\mathrm{P}+\mathrm{IR}+$ WLR - Re

$\mathrm{NFR}=7,00+2,00+0+2,2-2,31$

$$
=8,93
$$

$\mathrm{NFR}=(8,93 \times 10000) /(24 \times 60 \times 60)$

$\mathrm{NFR}=1,03$ liter/det/hari

Perhitungan pada periode JAN-1 (JAGUNG)

$>$ Diketahui,

- $\mathrm{P}=2.00$

- $\mathrm{S}=300 \mathrm{~mm}$

- $\mathrm{T}=30$ hari

- ET0 $=5,4 \mathrm{~mm} / \mathrm{hari}$

- $\mathrm{Re} \quad=4.60 \mathrm{~mm} / \mathrm{hr}$

NFR $=$ Penggunaan konsumtif $+\mathrm{P}+\mathrm{IR}+$ WLR - Re

$\mathrm{NFR}=5,5+0+0+0-4,60$

$=0,93$

$\mathrm{NFR}=(0,93 \times 10000) /(24 \times 60 \times 60)$

$\mathrm{NFR}=0.11$ liter/det/hari

\section{Perhitungan Kebutuhan Air Untuk Tiap} Petak Sawah (Existing)

Kebutuhan air untuk tanaman padi dilihat dari kebutuhan maksimal yaitu pada umur padi berusia dua bulan. Hasil pengukuran di lapangan diperoleh data tentang kebutuhan air dari masing-masing petak sawah pada umur padi berusia 10 harian sampai 4 bulan sebagai berikut.

[A $x$ NFR = Q keb]

- Total Kebutuhan air untuk Padi

$\sum$ sekunder $+\sum$ tersier $=\sum$ total $5121.04+942.06=6063.10 \mathrm{ltr} / \mathrm{det}$

- Total Kebutuhan air untuk Jagung

$\sum$ sekunder $+\sum$ tersier $=\sum$ total $1685.05+309.98=1995.03 \mathrm{ltr} / \mathrm{det}$

\section{Perhitungan Kebutuhan Air Setelah RTRW}

Setelah adanya program pemerintah terkait masalah pertumbuhan penduduk, maka pemerintah kabupaten Kepanjen membuat rencana tata ruang wilayah (RTRW). Pada program tersebut berakibat pada perubahan fungsi lahan yang semula persawahan menjadi pemukiman. Sedangkan petak sawah yang terkena akibat perubahan area tersebut adalah dari petak sawah A sampai $\mathrm{H}$.

Setelah adanya perubahan area lahan pertanian diatas akibat RTRW yang mengakibatkan berkurangnya area persawahan yang semula dari petak $\mathrm{A}-\mathrm{Z}$ adalah $3971 \mathrm{Ha}$, menjadi yang tersisa hanya petak $\mathrm{I}-\mathrm{Z}$ adalah 2178 Ha. Maka di dapat kebutuhan air total dari petak sawah $\mathrm{I}-\mathrm{Z}$ adalah :

$$
[\mathrm{A} \times \mathrm{NFR}=\mathrm{Q} \mathrm{keb}]
$$

- Total Kebutuhan air untuk Padi $\sum$ sekunder $+\sum$ tersier $=\sum$ total $2606.32+719.14=3325.47 \mathrm{ltr} / \mathrm{det}$

- Total Kebutuhan air untuk Jagung $\sum$ sekunder $+\sum$ tersier $=\sum$ total $857.60+236.63=1094.23 \mathrm{ltr} / \mathrm{det}$

Perhitungan ketersediaan air yang menggunakan metode FJ. Mock, maka didapat ketersediaan air tiap bulan di irigasi Molek tersebut adalah :

Tabel 3. Ketersediaan Debit Air Irigasi Molek Pada Kondisi Existing

\begin{tabular}{cccc}
\hline No & Bulan & $\begin{array}{c}\text { Qobs } \\
(\mathrm{m} 3 / \text { det })\end{array}$ & $\begin{array}{c}\text { Qmod } \\
(\mathrm{m} 3 / \text { det })\end{array}$ \\
\hline 1 & Jan & 12 & 119.826 \\
2 & Feb & 13.67 & 123.116 \\
3 & Mar & 15.15 & 96.525 \\
4 & Apr & 16.42 & 84.108 \\
5 & May & 11.96 & 59.402 \\
6 & Jun & 7.11 & 40.306 \\
7 & Jul & 6.11 & 24.547 \\
8 & Aug & 5.57 & 17.183 \\
9 & Sep & 5.61 & 12.429 \\
10 & Oct & 5.57 & 8.42 \\
11 & Nov & 6.28 & 10.899 \\
12 & Dec & 15.23 & 72.849 \\
\hline
\end{tabular}

Sumber : Hasil Perhitungan

\section{Kebutuhan Air Setelah RTRW - Ketersediaan Air}

Setelah adanya perubahan area lahan pertanian diatas akibat RTRW yang mengakibatkan berkurangnya area persawahan yang semula dari petak $\mathrm{A}-\mathrm{Z}$ adalah $3971 \mathrm{Ha}$, menjadi yang tersisa hanya petak $\mathrm{I}-\mathrm{Z}$ adalah 2178 Ha. Maka di dapat kebutuhan air total dari petak sawah I - Z adalah : 
- Total Kebutuhan air untuk Padi $\sum$ sekunder $+\sum$ tersier $=\sum$ total $2606.32+719.14=3325.47 \mathrm{ltr} / \mathrm{det}$

- Total Kebutuhan air untuk Jagung $\sum$ sekunder $+\sum$ tersier $=\sum$ total $857.60+236.63=1094.23 \mathrm{ltr} / \mathrm{det}$

Setelah adanya rencana tata ruang wilayah (RTRW) kabupaten Malang yang mengakibatkan berkurangnya luas baku sawah, dan dapat dilihat perhitungan antara kebutuhan dan ketersediaan air diatas. Dapat disimpulkan bahwa pada kondisi tersebut air yang mengaliri jaringan irigasi molek dianggap tetap sama pada kondisi existing tetapi karna luas area sawah yang diairi berkurang, maka jumlah air dianggap bisa melebihi kebutuhan air yang akan dimanfaatkan oleh para petani untuk mengairi sawah tersebut. Serta dapat digunakan untuk meningkatkan produksi padi di daerah tersebut.

\section{Pemanfaatan Keandalan Debit Bendung Blobo}

Kondisi debit yang masuk ke bendung blobo dari aliran kali Brantas itu sendiri jika dilihat dari data yang tercatat oleh UPTD Sumber Daya Air dan Irigasi kepanjen adalah :

Tabel 4. Rerata Debit Aliran Model FJ. Mock kali Brantas

\begin{tabular}{ccc}
\hline No & Bulan & $\begin{array}{c}\text { Qmod } \\
\text { (m3/det) }\end{array}$ \\
\hline 1 & Jan & 119.826 \\
2 & Feb & 123.116 \\
3 & Mar & 96.525 \\
4 & Apr & 84.108 \\
5 & May & 59.402 \\
6 & Jun & 40.306 \\
7 & Jul & 24.547 \\
8 & Aug & 17.183 \\
9 & Sep & 12.429 \\
10 & Oct & 8.42 \\
11 & Nov & 10.899 \\
12 & Dec & 72.849 \\
\hline
\end{tabular}

Sumber : Hasil Perhitungan
Tabel 5. Rerata Debit intake Bendung Blobo

\begin{tabular}{ccc}
\hline No & Bulan & $\begin{array}{c}\text { Debit } \\
(\mathrm{m} 3 / \text { det })\end{array}$ \\
\hline 1 & jan & 6.73 \\
2 & feb & 6.85 \\
3 & mar & 6.91 \\
4 & apr & 6.78 \\
5 & may & 6.55 \\
6 & jun & 6.63 \\
7 & jul & 6.56 \\
8 & aug & 6.31 \\
9 & sep & 5.72 \\
10 & oct & 5.45 \\
11 & nov & 5.88 \\
12 & dec & 6.26
\end{tabular}

Sumber : Hasil Perhitungan

Pada kondisi existing irigasi Molek memakai sistem pola tata tanam (PTT) musim hujan (MH) bulan Desember - Maret, musim kemarau 1 (MK 1) bulan April - Juli, dan musim kemarau 2 (MK 2) bulan Agustus November.

Untuk pembagian (PTT) antara Padi Tebu - Palawija pada kondisi yang terdata di Dinas Pengairan UPTD SDA dan Irigasi Kepanjen yang menggunakan luas baku sawah 3,971 (Ha) adalah :

Tabel 6. Pembagian Luasan Area Sawah Menurut Pembagian Musim Tanam

\begin{tabular}{ccccc}
\hline No & $\begin{array}{c}\text { Jenis } \\
\text { Tanaman }\end{array}$ & $\begin{array}{c}\text { MH } \\
(\mathrm{Ha})\end{array}$ & $\begin{array}{c}\text { MK 1 } \\
(\mathrm{Ha})\end{array}$ & $\begin{array}{c}\text { MK 2 } \\
(\mathrm{Ha})\end{array}$ \\
\hline 1 & Padi & 3,848 & 2,138 & 1,311 \\
2 & Tebu & 119 & 199 & 199 \\
3 & Palawija & - & 1,630 & 2,457 \\
4 & bero & 4 & 4 & 4 \\
5 & Total & 3,971 & 3,971 & 3,971 \\
\hline \multicolumn{5}{l}{ Sumber : Hasil Perhitungan }
\end{tabular}

Existing

$\mathrm{MH}=95 \%$

MK1 $=53 \%$

$\mathrm{MK} 2=33 \%$

\section{Akibat RTRW}

- Luas area sawah $\quad=2178 \mathrm{Ha}$

- Total kebutuhan air

$$
\text { ○ } \text { Padi }=3325.47 \mathrm{ltr} / \mathrm{det}
$$$$
\text { ○ Jagung }=1094.23 \mathrm{ltr} / \mathrm{det}
$$ 
- Rata - rata ketersediaan air kali Brantas

○ $\quad=$ MH (des - mar) $: 18,227$ ltr/det

$\circ \quad=$ MK1 (apr - jul) :14,088 ltr/det

○ $=$ MK2 (ags - nov) : 8,002 ltr/det

Jika dilihat dari tabel 4 dan 5 maka bisa dibuat grafik perbandingan sebagai berikut :

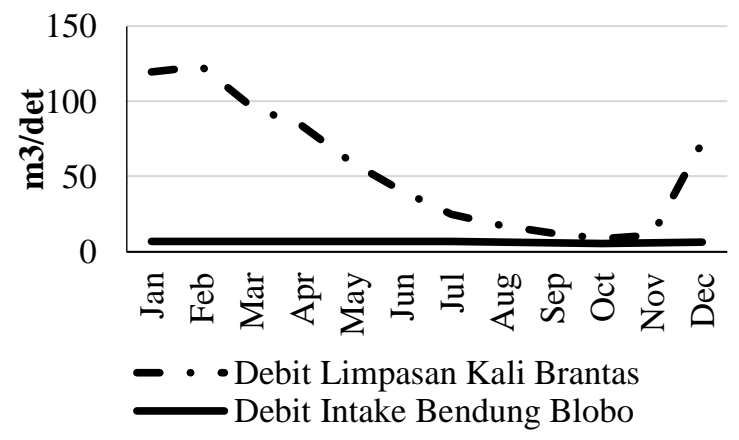

Gambar 6. Grafik Perbandingan Debit Aliran Sungai DAS Brantas Hasil Pendugaan Model F.J. Mock dan Debit intake Bendung Blobo (Penggunaan Lahan Eksisting Rata-rata Tahun 2005 - 2015)

\section{PEMBAHASAN}

Analisa ketersediaan Air

Pada perhitungan Analisa ketersediaan Air ini disimpulkan bahwa :

- Debit Yang melimpas di Kali Brantas

$$
\begin{array}{ll}
\text { MH } & =18,227 \mathrm{ltr} / \mathrm{det} \\
\text { MK1 } & =14,088 \mathrm{ltr} / \mathrm{det} \\
\text { MK2 } & =8,002 \mathrm{ltr} / \mathrm{det}
\end{array}
$$

- Debit yang masuk ke bendung Blobo

$$
\begin{array}{ll}
\text { MH } & =6.688 \mathrm{ltr} / \mathrm{det} \\
\text { MK1 } & =6.632 \mathrm{ltr} / \mathrm{det} \\
\text { MK2 } & =5.842 \mathrm{ltr} / \mathrm{det}
\end{array}
$$

\section{Kebutuhan air}

Dari hasil perhitungan NFR ini didapat bahwa kebutuhan untuk air pada PTT, didapat untuk padi $=1,909 \mathrm{l} / \mathrm{det} / \mathrm{Ha}$ dan jagung $=0,6281 /$ det $/ \mathrm{Ha}$

- Perhitungan Kebutuhan Air Untuk Tiap Petak Sawah (Existing)

Dengan kebutuhan air pada kondisi existing diatas, maka didapat kebutuhan air total dari petak sawah $\mathrm{A}-\mathrm{Z}$ adalah :

- Total Kebutuhan air untuk Padi $\sum$ sekunder $+\sum$ tersier $=\sum$ total $5121.04+942.06=6063.10 \mathrm{ltr} / \mathrm{det}$

- Total Kebutuhan air untuk Jagung $\sum$ sekunder $+\sum$ tersier $=\sum$ total $1685.05+309.98=1995.03$ ltr/det

- Perhitungan Kebutuhan Air Akibat RTRW

○ Total Kebutuhan air untuk Padi $\sum$ sekunder $+\sum$ tersier $=\sum$ total $2606.32+719.14=3325.47 \mathrm{ltr} / \mathrm{det}$

- Total Kebutuhan air untuk Jagung $\sum$ sekunder $+\sum$ tersier $=\sum$ total $857.60+236.63=1094.23 \mathrm{ltr} / \mathrm{det}$

\section{Analisa Keandalan Debit Bendung Blobo}

Pada perhitungan Analisa keandalan bendung blobo disimpulkan bahwa rata - rata air adalah :

- Debit yang melimpas di Kali Brantas

$\mathrm{MH}=18,227 \mathrm{ltr} / \mathrm{det}$

MK1 $=14,088 \mathrm{ltr} / \mathrm{det}$

MK2 = 8,002 ltr/det

- Debit yang masuk ke bendung Blobo

$\mathrm{MH}=6.688 \mathrm{ltr} / \mathrm{det}$

MK1 $=6.632 \mathrm{ltr} / \mathrm{det}$

$\mathrm{MK} 2=5.842 \mathrm{ltr} / \mathrm{det}$

\section{Pemanfaatan Keandalan Debit Bendung Blobo}

Apabila dilihat dari segi aspek ketersediaan - kebutuhan diatas maka bisa disimpulkan jika pada saat MK1 dan MK2 akibat RTRW, jumlah ketersediaan air masih cukup untuk meningkat kan jumlah padi yang ditanam bahkan hingga sampai $100 \%$ dari total lahan area yang tersedia. Tetapi mengingat adanya kebutuhan petani akan tanaman tebu dan palawija, tentunya hal tersebut akan berdampak pada hasil produksi para petani untuk tanaman tersebut jika semua area lahan di tanami padi.

Yang menjadi point penting pada analisa ini adalah, bahwa jika pada kondisi exstrem seperti musim kemarau pun para petani bisa saja memaksimalkan semua area lahan pertanian untuk ditanami oleh padi.

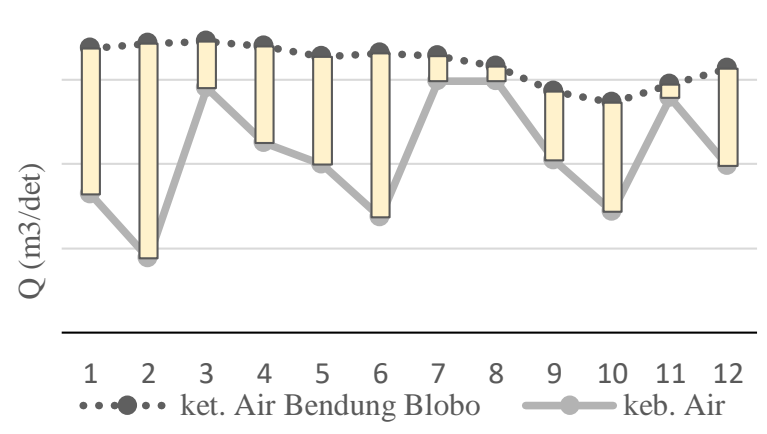

Gambar 7. Grafik Perbandingan Antara Ketersediaan Debit Air di Intake Bendung Blobo Dengan Kebutuhan Air Untuk Padi Pada Kondisi Existing 
Tabel 7. kelebihan Air

\begin{tabular}{cccc}
\hline No & Periode & Ex & RTRW \\
\hline 1 & Jan & 3.45 & 4.932 \\
2 & Feb & 5.088 & 5.885 \\
3 & Mar & 1.106 & 3.728 \\
4 & Apr & 2.289 & 4.319 \\
5 & May & 2.567 & 4.365 \\
6 & Jun & 3.899 & 5.133 \\
7 & Jul & 0.6 & 3.291 \\
8 & Aug & 0.345 & 3.037 \\
9 & Sep & 1.637 & 3.481 \\
10 & Oct & 2.594 & 3.886 \\
11 & Nov & 0.317 & 2.557 \\
12 & Dec & 2.303 & 4.088 \\
\hline
\end{tabular}

Pada gambar 7 tersebut bisa dilihat ada kelebihan air yang cukup banyak pada kondisi setelah RTRW yang kemudian dari kelebihan air tersebut bisa dimanfaatkan untuk meningkatkan pola tata tanam yang sudah ada. Terlihat juga perbandingan kelebihan air antara kondisi Existing yang memakai pola tata tanam awal dengan kondisi setelah RTRW, kemudia hasil dari kelebihan air tersebut menjadi bukti bahwa dengan adanya RTRW Kab. Malang yang mengakibatkan berkurangnya sebagian area lahan pertanian yang kemudia menimbulkan kelebihan air yang cukup banyak dan bisa dipakai untuk memaksimalkan pola tata tanam yang sudah ada.

\section{KESIMPULAN DAN SARAN Kesimpulan}

Setelah melakukan pengolahan data dari beberapa dinas terkait di kabupaten Malang, hasil survey dan data sekunder yang diperoleh, maka diambil kesimpulan sebagai berikut :

- Debit bendung Blodo itu sendiri bisa dikatakan andal apabila terjamin nya ketersediaan air di kali brantas dan yang masuk di bendung Blobo masih bisa melayani kebutuhan Irigasi Molek .

Secara perhitungan yang didapat dari analisa data disimpulkan bahwa kondisi minimal bendung blobo terjadi pada musim kering 2 (MK2) yaitu pada bulan Agustus - November dengan jumlah air $=5.842 \mathrm{ltr} / \mathrm{det}$ kemudian pada kondisi pertengahan yang terjadi pada musim kering 1 (MK1) bulan April - Juli jumlah air $=6.632$ ltr/det, dan pada kondisi jumlah air Maksimal terjadi pada saat musim hujan $(\mathrm{MH})$ yang terjadi pada bulan Desember - Maret.

- Dengan adanya perubahan luas area pertanian akibat rencana tata ruang wilayah kabupaten kepanjen, maka berakibat pada berkurangnya luas area lahan pertanian yang semula petak sawah tersebut memiliki petak $\mathrm{A}-\mathrm{Z}$, menjadi tersisa I - Z dengan luasan sejumlah 3971 Ha menjadi $2178 \mathrm{Ha}$.

- Pada kondisi Existing dengan luasan area pertanian sejumlah $3971 \mathrm{Ha}$ jumlah padi yang ditanam pada luas area persawahan adalah $\mathrm{MH}=95 \%$, $\mathrm{MK} 1=53 \%$, dan MK2 $=33 \%$

Sedangkan pada kondisi setelah adanya Rencana Tata Ruang Wilayah Kab. Malang Kec. Kepanjen, bahwa pada kondisi extreme pun petani masih bisa menggunakan $90 \%$ lebih luas sawah pada masing - petak sekunder ataupun tersier. Mengingat air yang masuk ke bendung blobo dan disalurkan ke Irigasi molek masih bisa mencukupi untuk petani memanfaatkan untuk menanam padi.

\section{Saran}

Penelitian ini dapat menjadi bahan masukan untuk mengoptimalkan pola tata tanam akibat RUTR kabupaten Malang dan menjadi masukan bagi daerah lain untuk sebagai reperensi dalam memaksimalkan pola tata tanam agar dalam pemanfaatan lahan bisa lebih maksimal. Selain daripada itu tugas akhir ini dapat meningkatkan wawasan bagi penulis bagaimana cara menyelesaikan masalah terkait dengan pengurangan area irigasi akibat dari rencana tata ruang wilayah kab. Malang.

\section{DAFTAR PUSTAKA}

Arikunto, Suharsimi. 2006. Manajemen Penelitian. Jakarta: Rineka Cipta. Direktorat Jendral

Mawardi, Erman. 2007. Desain Hidrolik Bangunan Irigasi. Jakarta: Alfabeta.

Peraturan Bupati Pati. 2011. Pedoman Pola Tanam Dan Rencana Tata Tanam. Pati.

Peraturan Pemerintah No. 25, 2001. Tentang Sumber Daya Air. Jakarta. Soematro, 1986. Hidrologi Teknik. Surabaya: Usaha Nasional. Sosrodarsono, S. 2003. Hidrologi untuk Pertanian. Jakarta: Pradya Paramita. 
Sudjarwadi. 1987. Dasar-Dasar Teknik Irigasi. Fakultas Teknik Universitas Gajahmada. Yogyakarta.

Sumber Daya Air. 1986. Standar Perencanaan Irigasi. Jakarta. DPU Pengairan. 2004. UU No.7 Tentang Sumber Daya Air. Jakarta.

Tancung, Andi Baso dan Kurdi, M. Gufron. 2005. Pengelolaan Kualitas Air dalam Budi Daya Perairan. Makasar: Rineka Cipta.

Triatmojo, B. 1996. Hidraulika I, Fakultas Teknik Universitas Gajahmada. Yogyakarta. 